\title{
Strategies for nurse retention in hospitals: scoping review protocol
}

Estratégias de retenção de profissionais de enfermagem nos hospitais: protocolo de scoping review

Estrategias de retención de los profesionales de enfermería en los hospitales: protocolo de revisión exploratoria

Letícia Helena do Nascimento*(D) Grazia Maria Guerra**(D) Janaina Gomes Perbone Nunes***iD;

Diná de Almeida Lopes Monteiro da Cruz ${ }^{* * * *}$ (D)

\begin{abstract}
Background: Nursing turnover has an impact on the quality of care, patient safety, and hospital productivity. Objective: To map nursing staff retention strategies in hospitals.

Method of review: Scoping review protocol according to the Joanna Briggs Institute method. Published and unpublished bibliographical material according to the following inclusion criteria: reporting the use of strategies for retention (concept) of nursing professionals (population) in hospitals (context). The sources of data will be: MEDLINE, EMBASE, CINAHL, CENTRAL, LILACS, PsycINFO, ProQuest Dissertations, Theses Database, TRIP, International Council of Nurses, Google academic, and Capes Thesis Catalog. Two reviewers will screen the titles and abstracts, read the full texts, and extract the data from the included material. The data will be grouped into categories according to their contents.

Presentation and interpretation of results: The analyzed data will be presented in a diagrammatic, tabular, and narrative form.
\end{abstract}

Conclusion: It will contribute to the management decision making regarding the turnover of nursing personnel.

Keywords: nurses; personnel turnover; hospitals; review

\section{Resumo}

Enquadramento: A rotatividade de enfermagem tem impacto na qualidade do cuidado, na segurança do paciente e na produtividade dos hospitais.

Objetivo: Mapear as estratégias de retenção do pessoal de enfermagem nos hospitais.

Método de revisáo: Protocolo de scoping review segundo o método do Joanna Briggs Institute. Serão considerados materiais bibliográficos publicados e não publicados, conforme os seguintes critérios de inclusão: relatar o uso de estratégias para retenção (conceito) de profissionais de enfermagem (população) em hospitais (contexto). Serão fontes de dados: MEDLINE, EMBASE, CINAHL, CENTRAL, LILACS, PsycINFO, ProQuest Dissertations, Theses Database, TRIP, International Council of Nurses, Google Académico e Catálogo de Teses da Capes. Dois revisores triarão os títulos e resumos, lerão os textos completos e extrairão os dados do material incluído. Os dados serâo reunidos em categorias de acordo com os seus conteúdos.

Apresentaçáo e interpretaçáo dos resultados: Os dados analisados serão apresentados de forma diagramática, tabular e narrativa.

Conclusáo: Contribuirá para a tomada de decisóes gerenciais relativas à rotatividade de pessoal de enfermagem.

Palavras-chave: enfermeiros; rotatividade de pessoal; hospitais; revisão

*MSc., Enfermeira, Centro Universitário São Camilo, São Paulo - SP, 04263-200, Brasil [lecaviduo@gmail.com]. (Dhttps://orcid.org/0000-0003-0930-955X. Contribuição no artigo: pesquisa bibliográfica, recolha de dados, análise e discussão dos dados e escrita do artigo. Morada para correspondência: Av. Padre Arlindo Vieira, 1035, São Paulo-SP, 04297-000, Brasil. **Ph.D., Enfermeira, Centro Universitário São Camilo, São Paulo - SP, 04263-200, Brasil [enfmestrado@saocamilo.sp.pt]. (1) https://orcid.org/0000-0003-4131-7904. Contribuição no artigo: análise e discussão dos dados e escrita do artigo.

***Ph.D., Enfermeira, Escola de Enfermagem da Universidade de São Paulo, São Paulo - SP, 05403-000, Brasil [janaina.perbone@usp.br]. D https://orcid.org/0000-0001-6909-6264. Contribuição no artigo: pesquisa bibliográfica, recolha de dados, análise e discussão dos dados e escrita do artigo.

****Ph.D., Enfermeira, Escola de Enfermagem da Universidade de São Paulo, São Paulo - SP, 05403-000,Brasil [dinamcruz@usp.br]._o https://orcid.org/0000-0003-1373-409X. Contribuição no artigo: Contribuição no artigo: análise e discussão dos dados e escrita do artigo.

\section{Resumen}

Marco contextual: La rotación de enfermeros tiene un impacto en la calidad de la atención, la seguridad de los pacientes y la productividad de los hospitales.

Objetivo: Mapear las estrategias de retención del personal de enfermería en los hospitales.

Método de revisión: Protocolo de revisión exploratoria según el método del Instituto Joanna Briggs. Se considerarán los materiales bibliográficos publicados y no publicados, de acuerdo con los siguientes criterios de inclusión: informar sobre el uso de estrategias de retención (concepto) de los profesionales de enfermería (población) en los hospitales (contexto). Las fuentes de datos serán: MEDLINE, EMBASE, CINAHL, CENTRAL, LILACS, PsycINFO, ProQuest Dissertations, Theses Database, TRIP, International Council of Nurses, Google Académico y Catálogo de Tesis de la Capes. Dos revisores clasificarán los títulos y resúmenes, leerán los textos completos y extraerán los datos del material incluido. Los datos se recogerán en categorías según su contenido.

Presentación e interpretación de los resultados: Los datos analizados se presentarán en forma de diagrama, tabla y narrativa.

Conclusión: Contribuirá a la toma de decisiones de gestión en relación con la rotación del personal de enfermería.

Palabras clave: enfermeras; reorganización del personal; hospitales; revisión

Received for publication: 03.06 .19

Accepted for publication: 26.07.19 


\section{Introduction}

Strategies for nurse retention seek to reduce the turnover of this staff quota in health services and are essential for quality and financial outcomes of hospitals. Investments in nurse retention favor quality of service, patient safety, and hospital productivity (Dewanto \& Wardhani, 2018; Park, Park, \& Hwang, 2019). This review protocol addresses strategies that have been implemented to control nursing staff turnover in hospitals.

Staff turnover consists of personnel change due to reorganization, dismissal, or resignation. It can be classified as voluntary or involuntary, meaning: the former occurs on the initiative of the employee; the latter occurs on the initiative of the employer. It can also be classified as functional and dysfunctional. When a leaving worker creates an increase of value to the company, the turnover is functional; when it causes decreased value, for example, when a high-performance employee is hard to replace, the turnover is dysfunctional. The turnover rate is calculated by summing up the monthly turnover of 12 months. The monthly turnover is calculated by dividing the number of one month's official contract cancellations for the overall mean of active employees during that month (Cascio \& Boudreau, 2010).

Nursing staff turnover is a global concern, since the nursing profession is considered vital for the functioning of health services, and professionals' turnover, when not controlled, can become damaging and costly for the institutions (Foster, 2017). The International Council of Nurses (ICN) recommends that organizations ensure the health, safety, personal well-being, and motivation of workers, as well as the quality of healthcare provided to patients. According to the ICN, positive changes in the work environment lead to professional satisfaction, resulting in lower turnover rates (Buchan, Shaffer, \& Catton, 2018).

The factors associated with nursing staff turnover in health services include individual factors (such as gender, age, marital status, job satisfaction); work-related factors (such as workload, working conditions, role ambiguity, promotional opportunities); interpersonal factors (such as supervisor support, management style, praise and recognition, confidence); and organizational factors (such as work environment, organizational climate, financial determinants; Galletta, Portoghese, Carta, D'Aloja, \& Campagna, 2016; Halter et al., 2017; Portoghese, Galletta, Battistelli, \& Leiter, 2015). Studies have demonstrated that job satisfaction is probably the most important factor associated with the intention to leave work, or even the career. According to Portoghese et al. (2015), the more motivating the work environment and professional valorization are (for example, more autonomy, opportunities to use different skills, and recognition of the work performed), the more satisfied nurses feel. Leaders should promote the worker's autonomy and team collaboration, establish effective communication, promote accountability, provide opportunities to contribute to the decision-making processes, and consider the clinical skills of nurses (Portoghese et al., 2015). In turn, the work environment seems to play a vital role for the nurse's job satisfaction. Galletta et al. (2016) noted that the collective perception of a positive work environment among professionals promotes the sense of self and team commitment of nurses and reduces the intention to leave. It is essential to underline the high organizational costs related to staff management processes resulting from the turnover (training of people, recruitment, and selection for personnel renewal; Halter et al., 2017). The cost of turnover involves the pre-hiring (notice, recruitment, vacancies, and hiring) and post-hiring processes (guidance, training, reduced productivity of new employees, cancellations, and rescissions; Ruiz, Perroca, \& Jericó, 2016). A case study conducted in Brazil aimed to map the sub-processes related to the nursing team turnover and measure their costs (Ruiz et al., 2016). The results showed that the financial impact of a collaborator's contract cancellation costs three times the average salary of the nursing team. The most considerable burden identified in that research was related to the post-hiring process and corresponded to the reduced productivity of the newly admitted employee (Ruiz et al., 2016).

Although often regarded as undesirable, the turnover is somewhat beneficial because it avoids the stagnation of the organization (Weisman, Alexander, \& Chase, 1981). There is no consensus regarding the appropriate rates of nursing 
staff turnover. Ideally, the turnover rate should allow the institution to retain the talents and replace the low-performance collaborators (Ruiz et al., 2016).

The hospital sector is one of the most affected by nursing staff turnover. Nursing Solutions (NSI, 2019) published in March 2019 the turnover data of 221 hospitals in the United States of America, emphasizing that the 2018 hospital turnover increased by $0.9 \%$ compared to 2017, representing the worst of the decade (NSI, 2019). Also according to NSI (2019), in 2018, the medical healthcare labor market has grown and tends to continue to rise in 2019 , anticipating the possible loss of health professionals' workforce from hospitals to other healthcare settings. The health professionals' turnover rate in hospitals of the United States of America in 2018 was 19.1\%, and an agreement between hospitals was established to reduce the turnover by $3.26 \%$ in 2019 . Like health professionals' turnover in hospitals in general, the nursing turnover increased (NSI, 2019). The nursing staff turnover rate grew from $16.8 \%$ in 2017 to $17.2 \%$ in 2018 . Its highest rate (23.1\%) was among the specialist nurses who work in behavioral health (NSI, 2019).

In 2015, a report of the English National Health Service (NHS, 2015) was published containing nursing turnover data of 147 nursing health services, from November 2014 to December 2015. The data indicated that $74 \%$ of the services had a nursing turnover rate of up to $15 \%$, which was considered positive. It is important to highlight that $99 \%$ of the services investigated by the NHS have strategies for the retention of the deployed nursing team. Of the services that adopted retention strategies, 94\% focused on recruitment, $91 \%$ on work environment, $88 \%$ on staff relationships/development, and $50 \%$ on compensation/recognition (NHS, 2015). In Brazil, the nursing team turnover rates observed in a sample of 35 small, medium, and large hospitals, from 2016 to 2018, were the following, according to the annual medians: 2016 (14.42\%), 2017 (12.85\%), and 2018 (16.08\%), that is, the nursing turnover rate in hospitals has increased by $3.23 \%$ between 2017 and 2018, according to data from the Commitment to Hospital Quality program (Compromisso com a Qualidade Hospitalar, 2018).
Because the nursing staff turnover is influenced by several factors and needs to be managed, it is necessary to map the strategies that have been used in hospitals to keep the turnover rates appropriate.

The search in the PUBMED, Cochrane, CINAHL, JBI, and PROSPERO databases was carried out and did not identify reviews aimed at mapping the strategies implemented in hospitals to deal with the nursing staff turnover. Two systematic reviews were found on similar topics. One intended to verify the factors associated with the nursing professionals' intention to leave (Chan, Tam, Lung, Wong, \& Chau, 2013), and the other focused on the effectiveness of strategies for the retention of experienced nursing staff (Lartey, Cummings, $\&$ Profetto-Mcgrath, 2014). The interest in this protocol will extend the results of these reviews. Firstly, it is because it will focus on mapping the interventions that have been applied, regardless of whether results of their effects were presented, which is necessary for effectiveness reviews. Secondly, effectiveness reviews require a certain degree of homogeneity between studies regarding the interventions, which limits the inclusion of studies. Thirdly, the interest in this protocol is about interventions for retention of any nursing professional and not just the experienced ones (Lartey et al., 2014). A scoping review was also identified on the factors that affect the nursing staff's work motivation (Baljoon, Banjar, \& Banakhar, 2018), and a scoping review protocol on the retention of nursing students in their learning programs (Mitchell et al., 2019). This protocol will not address the factors that influence the nursing staff's work motivation, like in the scoping review by Baljoon et al. (2018), but the interventions that have been undertaken to retain nursing staff. This protocol also differs from the protocol by Mitchell et al. (2019), concerning the population of interest. In this protocol, the population of interest is nursing professionals in hospitals, and in that by $\mathrm{Mi}-$ tchell et al. (2019), the population is nursing students in educational institutions.

Because adopting strategies for the retention of nursing professionals and the existing knowledge on the topic are of great importance, this scoping review aims to map the existing knowledge on the strategies of nurse retention 
in hospitals. More specifically, this review aims to answer the following question: What strategies have been implemented to improve nurse retention in hospitals?

\section{Systematic review method}

Scoping reviews (also scoping studies) aim to map the main concepts that support a specific area of knowledge; to assess the extent, scope, and nature of the research in a specific area; to summarize and disseminate research data and identify gaps of existent researches, as well as to provide an overview of the existent evidence (Peters et al., 2017).

The scoping review is a method of knowledge synthesis, which incorporates different study designs comprehensively, summarizes and synthesizes evidence, informing practices, programs, and policies, in addition to guiding research priorities. Scoping reviews can contribute to the advancement of knowledge on healthcare practices, policies, and research. This scoping review will follow the methodological recommendations of the Joanna Briggs Institute Reviewer's Manual (Peters et al., 2017).

\section{Search strategy and study identification}

The research question was framed according to PICO (P: population, I: intervention, C: comparison, O: outcomes,) and adapted to PCC (P: population, C: concept, and C: context), according to the guidelines of the JBI's Manual (Peters et al., 2017). "P" refers to the population (nursing professionals), " $C$ " to the concept of interest (nurse retention strategies), and " $\mathrm{C}$ " to the context (hospitals). The inclusion criteria were established in accordance with the components of the research question. The review will consider studies that include nursing professionals as the focus of the retention strategy, regardless of demographic and occupational variables such as gender, age, race, education/training level, professional category, area of expertise, institutional affiliation, and a period of professional experience. The review will consider studies reporting the use of any strategy designed to impact or which has impacted nurse retention. Professionals' retention means the ability of a company to keep its employees and prevent them from going to work in another place. In relation to context, studies performed in hospitals will be considered, regardless of the type of establishment, the size of the institution, public or private, educational or not, general or specialized, rural or urban, and certified or not. The types of studies considered for inclusion will be the primary or secondary, quantitative and qualitative researches, and experience reports. Experience reports are understood as any description of a specific experience that does not have a formal definition of scientific research. The date of publication will have no limitations. Studies whose full text is accessible without cost to the researcher and written in English, Spanish, or Portuguese will be included.

The search strategy will be comprehensive to identify published and unpublished (gray literature) studies, as well as reviews and opinions or recommendations. It will be carried out in three stages: the first search will be in MEDLINE via PubMed and in CINAHL via EBSCO. For MEDLINE, the following strategy will be used: "nurses" [All Fields] AND "personnel turnover" [All Fields] AND "hospitals" [All Fields], and for CINAHL the strategy equivalent to that used for the MEDLINE. The titles, abstracts, and index terms of records retrieved with this initial search will be analyzed to identify alternative terms (keywords and index terms) to the terms of inclusion criteria.

In the second stage, all keywords and index terms identified will be used for the searches in the following sources: MEDLINE ${ }^{\odot}$ (Medical Literature Analysis and Retrieval System Online/PubMed, EMBASE $^{\oplus}$ (Elsevier); CINAHL ${ }^{\oplus}$ (Cumulative Index to Nursing and Allied Health Literaturel EBSCO); CENTRAL ${ }^{\oplus}$ (The Cochrane Central Register of Controlled Trials The Cochrane Library); LILACS $^{\circledast}$ (Literature in the Health Sciences in Latin America and the Caribbean/BVS - Virtual Health Library); PsycINFO ${ }^{\circledR}$, American Psychological Association; Portal of Capes (Coordination of High-Level Personnel Improvement); Google Scholar ${ }^{\circledR}$ ProQuest Dissertations; Theses Database; TRIP (Turning Research into Practice) database; International Council of Nurses website.

In the third stage, a search will be carried out for additional studies in the reference lists of all publications included in the review. If more information beyond what is published is necessary, the reviewers will contact the authors of the materials included. A librarian will narrow the strategy. Studies will be selected by two independent re- 
viewers based on the titles and abstracts (when available), according to the inclusion criteria described above. Any possible disagreements will be solved by consensus or by decision of a third reviewer to confirm the eligibility of a particular publication. In case of doubt, the material will be subject to full-text reading, which will provide more elements for the decision as to the relevance of the material to the review. Because it is a scoping review, the methodological quality of the studies will not be assessed (Peters et al., 2017).

The entire selection process of the studies will be represented in a flow chart adapted from the Preferred Reporting Items for Systematic Reviews and Meta-analyses (Moher, Liberati, Tetzlaff, Altman, \& Group, 2009).

\section{Data extraction}

The full texts of eligible publications will be retrieved and read by two reviewers who will confirm their pertinence and will make the extract of data of interest related to the review objectives, using an instrument developed specifically for this purpose (Figure 1). The instrument is preliminary and may be altered, adding data deemed pertinent over the reading of the publications. A pilot test will be conducted in as many publications as necessary so that the reviewers are familiar with the extraction tool.

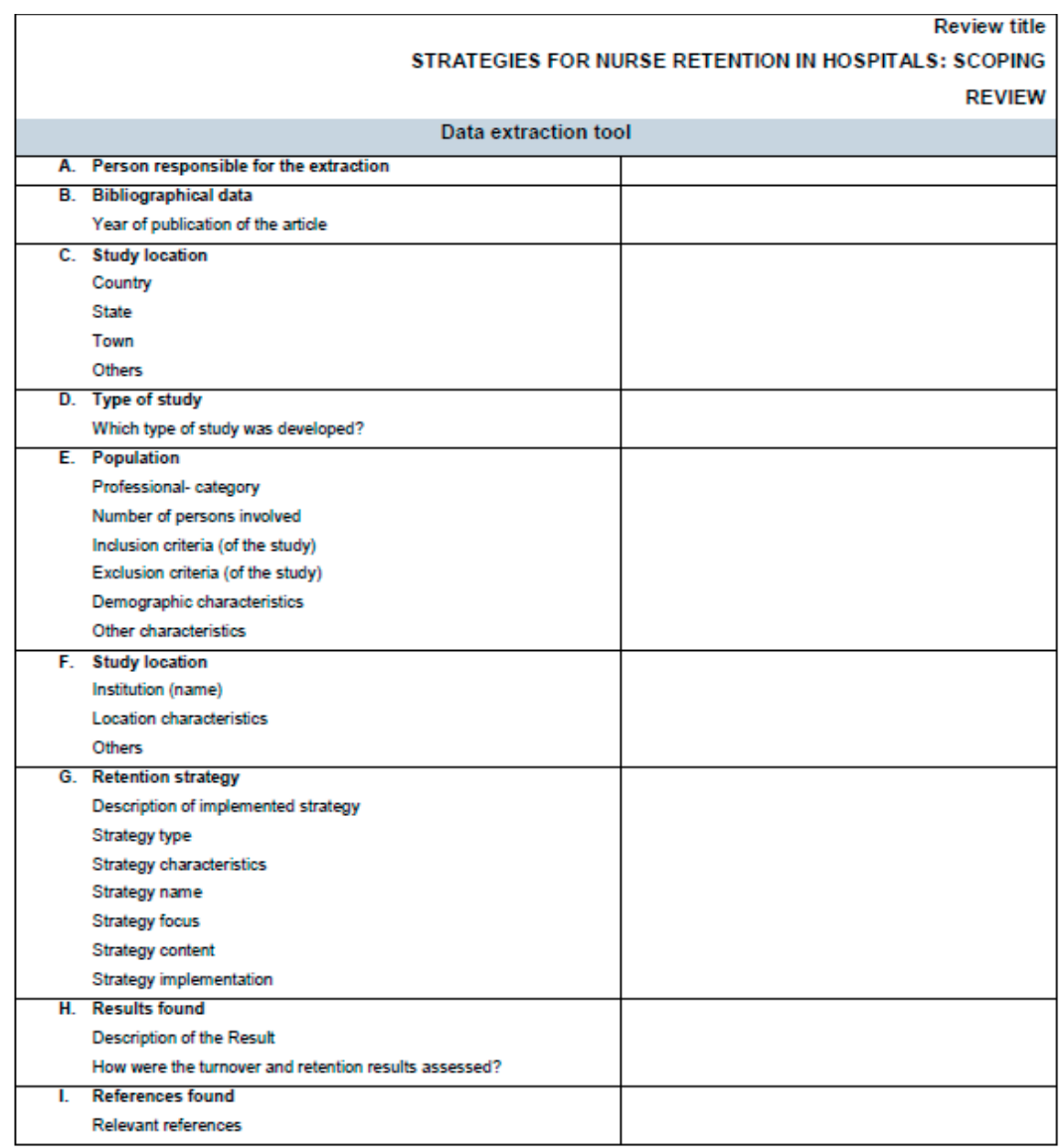

Figure 1. Data extraction tool 


\section{Data synthesis}

According to Halas et al. (2015), the sole purpose of a scoping review is to gather the results and provide an overview, rather than a meta-synthesis. Thus, the data extracted from the included documents shall be presented in tabular or diagrammatic form and/or in narrative form, depending on the purpose of the review, to report the results and summary of the analysis.

\section{Presentation and interpretation of results}

The results will be presented in narrative form and, whenever possible, in tables and graphs to summarize the nurse retention strategies being adopted in hospitals.

This scoping review may contribute to the decision-making of managers, educators, and even clinicians involved in improving nurse retention in hospitals.

\section{Conclusion}

As adopting strategies for professionals' retention and the existing knowledge on the topic are of great importance, this review will present results that can be used in projects and policies relating to nursing staff retention in hospitals. Because it is a review of the existing literature, this protocol does not involve humans and, as such, does not require consideration and opinion of a Research Ethics Committee. This study has no relation to funding institutions that may reveal potential conflicts of interest. The authors have no direct or indirect relation to the sponsoring institution of the research topic or companies that may benefit from its results.

\section{References}

Baljoon, R., Banjar, H., \& Banakhar, M. (2018). Nurses' work motivation and the factors affecting It: A scoping review. International Journal of Nursing \& Clinical Practices, 5(1). doi:10.15344/2394-4978/2018/277

Buchan, J., Shaffer, F. A., \& Catton, H. (2018). Policy brief: Nurse retention. Retrieved from https://www.icn.ch/
sites/default/files/inline-files/ICNM Nurse retention FINAL.pdf

Cascio, W., \& Boudreau, J. (2010). Investimento em pessoas: Como medir impacto financeiro das iniciativas em recursos humanos. Porto Alegre, Brasil: Bookman.

Chan, Z. C., Tam, W. S., Lung, M. K., Wong, W. Y., \& Chau, C. W. (2013). A systematic literature review of nurse shortage and the intention to leave. Journal of Nursing Management, 21(4), 605-613. doi:10.1111/ j.1365-2834.2012.01437.x

Compromisso com a Qualidade Hospitalar. (2018). Indicadores hospitalares: Compromisso com a qualidade hospitalar. Retrieved from http://www.cqh.org.br/ portal/pag/area.php?p_narea $=98$

Dewanto, A., \& Wardhani, V. (2018). Nurse turnover and perceived causes and consequences: A preliminary study at private hospitals in Indonesia. BMC Nursing, 17(Suppl 2), 1-7. doi:10.1186/s12912-018-0317-8

Foster, S. (2017). Making retention strategies work. British Journal of Nursing, 26(4), 251. doi:10.12968/ bjon.2017.26.4.251

Galletta, M., Portoghese, I., Carta, M. G., D’Aloja, E., \& Campagna, M. (2016). The effect of nurse-physician collaboration on job satisfaction, team commitment, and turnover intention in nurses. Research in Nursing and Health, 39(5), 375-385. doi:10.1002/nur.21733

Halas, G., Schultz, A. S. H., Rothney, J., Goertzen, L., Wener, P., \& Katz, A. (2015). A scoping review protocol to map the research foci trends in tobacco control over the last decade. BMJ Open, 5, e00643. doi:10.1136/ bmjopen-2014-006643

Halter, M., Boiko, O., Pelone, F., Beighton, C., Harris, R., Gale, J., ... Drennan, V. (2017). The determinants and consequences of adult nursing staff turnover: A systematic review of systematic reviews. BMC Health Services Research, 17(1), 824. doi:10.1186/s12913017-2707-0

Lartey, S., Cummings, G., \& Profetto-Mcgrath, J. (2014). Interventions that promote retention of experienced registered nurses in health care settings: A systematic review. Journal of Nursing Management, 22(8), 1027-1041. doi:10.1111/jonm.12105

Mitchell, K. M., Chorney, M. A., Gural, D. M., Simmons-Swinden, J. M., Picheca, L., \& Baxter, C. E. (2019). Social and academic integration strategies for retention of nursing students: A scoping review protocol. JBI Database of Systematic Reviews and Implementation Reports, 17(1), 28-36. doi:10.11124/ JBISRIR-2017-003745

Moher, D., Liberati, A., Tetzlaff, J., Altman, D. G., \& Group, T. P. (2009). Preferred reporting items for systematic reviews and meta-analyses: The PRISMA 
statement. Annals of Internal Medicine, 151(4), 264269. Retrieved from https://annals.org/aim/article-abstract/744664

National Health Service. (2015). NHS registered nurse supply and demand survey findings. Retrieved from https:// www.evidence.nhs.uk/document?id=2106886\&returnUrl=search $\% 3$ Fpa $\% 3$ D 5\%26ps\%3D20\%26q\%3Dnurse $\% 2 B$ staffing\&q=nurse+staffing

Nursing Solutions. (2019). 2019 national healthcare retention \& RN staffing report. Retrieved from http:// www.nsinursingsolutions.com/Files/assets/library/retention-institute/2019\%20National $\% 20$ Health $\% 20$ Care\%20Retention\%20Report.pdf

Park, J. H., Park, M. J., \& Hwang, H. Y. (2019). Intention to leave among staff nurses in small- and medium-sized hospitals. Journal of Clinical Nursing, 28(9-10), 1856-1867. doi:10.1111/jocn.14802

Peters, M., Godfrey, C. McInerney, P., Baldini Soares, C.,
Khalil, H., \& Parker, D. (2017). Scoping reviews. In Joanna Briggs Institute reviewer's manual. Retrieved from https://wiki.joannabriggs.org/display/MANUAL/ Chapter+11\%3A+Scoping+reviews

Portoghese, I., Galletta, M., Battistelli, A., \& Leiter, M. P. (2015). A multilevel investigation on nursing turnover intention: The cross-level role of leader-member exchange. Journal of Nursing Management, 23(6), 754764. doi:10.1111/jonm.12205

Ruiz, P. B., Perroca, M. G., \& Jericó, M. C. (2016). Cost of nursing turnover in a teaching hospital. Revista da Escola de Enfermagem da USP, 50(1), 104-111. doi:10.1590/S0080-623420160000100014

Weisman, C. S., Alexander, C. S., \& Chase, G. A. (1981). Evaluating reasons for nursing turnover: Comparison of exit interview and panel data. Evaluation \& the Health Professions, 4(2), 107-127. doi:10.1177/016327878100400201 
